\title{
CARACTERIZAÇÃO DAS PLANÍCIES DE MARÉS DO LITORAL CENTRO-SUL DE SERGIPE A PARTIR DAS SÉRIES AMBIENTAIS GEOMORFOLÓGICAS
}

\author{
Geisedrielly Castro dos Santos* \\ Universidade Federal de Sergipe
}

Rosemeri Melo e Souza**
Universidade Federal de Sergipe $^{* * t}$

Resumo: Cada planície de maré possui assinatura energética própria e semelhanças quanto aos seus aspectos geomorfológicos, de acordo com os agentes hidrodinâmicos que predominam sobre esses ambientes. 0 presente trabalho teve como objetivo caracterizar as planícies de marés do litoral centro-sul sergipano dentro das séries ambientais geomorfológicas, a partir dos agentes ambientais predominantes. Os procedimentos metodológicos da pesquisa foram: coleta de dados relativos à assinatura energética; processamento das imagens de satélite e fotografias aéreas; análise, integração e interpretação dos dados. Os resultados mostraram que, apesar de possuírem assinaturas energéticas semelhantes, ou seja, padrões semelhantes de: temperatura; precipitação; regime de marés; ondas; tensores antrópicos e ambientais, a existência de padrões diferentes de vazões fluviais foi determinante para alterações nos processos de configuração das desembocaduras fluviais analisadas e, consequentemente, para formação das planícies de marés. A referida análise é corroborada por estudos já efetuados sobre a morfodinâmica das desembocaduras analisadas. A partir das séries ambientais costeiras, a área de estudo foi classificada em: Ambiente dominado por ondas (desembocadura dos rios Sergipe e Piauí/Real) e Ambiente dominado por ondas e rio (desembocadura do rio Vaza Barris). A partir dessa classificação foi possível mensurar o grau de resistência e resiliência dos manguezais associados, respectivamente, sendo de baixo e médio/ baixo grau para os ambientes dominados por ondas, e de médio e médio/alto grau para os ambientes dominados por ondas e rios. Esta pesquisa fornece subsídios para o monitoramento de sistemas ambientais costeiros associados a áreas com tendências a crescimento urbano.

\section{CHARACTERIZATION OF TIDAL FLATS IN THE CENTRAL- SOUTH COAST OF SERGIPE FROM GEOMORPHOLOGICAL ENVIRONMENTAL SERIES}

Abstract: Each tidal flat has its own energy signature and has similarities regarding its geomorphological aspects, according to the hydrodynamic agents that predominate in these environments. This study aims to characterize the tidal flats in the central-south coast of Sergipe within the geomorphological environmental series from the prevailing environmental agents. The methodological procedures of the research study were: data collection regarding the energy signature; satellite images and aerial photographs processing; analysis and integration, data interpretation. The results showed that - despite having similar energy signature, that is, similar patterns of temperature, precipitation, tidal regime, waves, anthropic and environmental tensors - the existence of different river flow patterns were instrumental in changing the configuration processes of the analyzed river mouths and consequently the formation of tidal flats. This analysis is supported by previous studies on the morphodynamics of the analyzed river mouths. From the coastal environmental series, the study area can be classified into: environment dominated by waves (mouths of Sergipe and Piauí/Real Rivers) and environment dominated by waves and river (mouth of Vaza Barris River). Based on this classification, it was possible to measure the degree of resistance and resilience of the associated mangroves, respectively: low and medium/low level for environments dominated by waves, and medium to medium/high level for environments dominated by waves and rivers. This research study provides instruments for monitoring of coastal environmental systems associated with areas which tend towards urban growth.

Keywords: Mangrove. Estuarine dynamics. Energy signature. 
Um Estuário é definido por Pritchard (1967) como sendo um corpo semifechado de água costeira que tem uma ligação livre com o mar aberto e na qual a água do mar é mensuravelmente diluída com a água doce, sendo esta originária de uma drenagem fluvial. A ocorrência de ambientes de planícies de marés em zonas estuarinas e posterior colonização pela vegetação acontecem quando existem áreas abrigadas da ação mecânica das ondas e que sofrem a influência do regime de marés (Zenkovich, 1967; Angulo, 1990).

Thom (1982) propôs a modelagem de cinco séries ambientais costeiras, nas quais as planícies de marés estão inseridas, sendo estas determinadas pelos componentes geofísicos, geomórficos e biológicos. O componente geofísico remete aos parâmetros oceanográficos em associação com os movimentos terrestres e influência do regime climático. 0 componente geomórfico corresponde ao produto da interação dos fatores geofísicos que modelaram a superfície da Terra e na qual atuam os processos geomórficos atuais, sendo estes últimos os determinantes das condições do hábitat dos mangues. 0 componente biológico refere-se a reserva de espécies e a competição entre elas. Este último componente se mostra fundamental diante do potencial de recuperação do manguezal em situações de estresse ambiental, podendo suprir a necessidade de novos indivíduos em caso de morte por competição com outras espécies. As séries ambientais idealizadas por Thom (1982) levam em consideração a predominância dos agentes fluviomarinhos em conformidade com todos os componentes principais citados: Série I - Ambiente dominado por rios; Série II - Ambiente dominado por marés; Série III - Ambiente dominado por ondas; Série IV - Ambiente dominado por ondas e rios; Série V - Vales afogados.

A planície costeira do estado de Sergipe (assim como em todo o País) teve seu processo de formação associado às flutuações do nível relativo do mar durante o Quaternário (Suguio; Martin, 1978). Para o estado de Sergipe, um modelo esquemático foi produzido por Bittencourt et al. (1983) para refletir esse processo de formação a partir das transgressões e regressões marinhas. Os principais eventos associados à evolução paleogeográfica quaternária foram responsáveis por: Retrabalhamento da Formação Barreiras; Afogamento dos vales fluviais; Deposição dos sedimentos no sopé das falésias formadas, conjuntamente com materiais de origem orgânica; Deposição de sedimentos de origem eólica e Formação dos terraços marinhos pleistocênicos e holocênicos.

Cortando toda a planície costeira do estado de Sergipe existem seis desembocaduras fluviais, modeladas a partir dos processos de transgressões e regressões marinhas e dentro das quais se originaram ambientes de planícies de marés colonizados pela vegetação de mangue, dando origem aos manguezais. Contudo, esses ambientes se diferenciam de acordo com a predominância dos agentes fluviomarinhos, sejam eles ligados ao fluxo fluvial, energia das ondas e regime de marés, conforme descrito em Thom (1982).

A partir da investigação dos fatores mencionados é possível identificar qual o agente predominante na dinâmica estuarina e assim caracterizar a série ambiental geomorfológica. Essa análise serve como aporte para compreender a resistência e a resiliência dos manguezais que se desenvolvem nesses estuários, permitindo uma análise comparativa em nível regional e global.

\section{Área de estudo}

A pesquisa desenvolvida no presente trabalho possui como recorte espaçotemporal as planícies de marés do litoral centro-sul de Sergipe, localizadas entre as latitudes $10^{\circ} 50^{\prime} \mathrm{S}$ e $11^{\circ} 30^{\prime} \mathrm{S}$ e entre as longitudes $37^{\circ} \mathrm{W}$ e $37^{\circ} 30^{\prime} \mathrm{W}$. As referidas planícies de marés situam-se nas zonas estuarinas das desembocaduras dos rios: Sergipe (município de Aracaju/SE); Vaza Barris (municípios de Aracaju e Itaporanga D'Ajuda) e Piauí/Real (municípios de Estância, Santa Luzia do Itanhy e Indiaroba) (Figura 1).

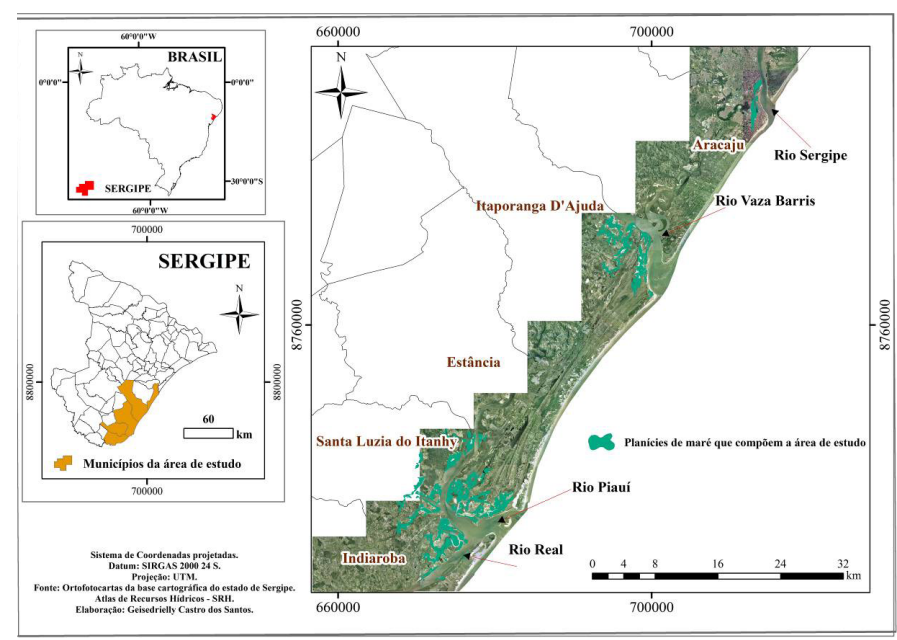

Figura 1 - Localização da área de estudo. Sergipe/Brasil. Fonte: organização dos autores.

As desembocaduras fluviais que compõem a área de estudo possuem seus processos de formação explicados pelos mecanismos de transporte de sedimentos em desembocaduras fluviais proposto por FitzGerald (1982) e revisto por FitzGerald, Kraus e Hands (2000). Dentre os nove modelos propostos, as desembocaduras estudadas enquadram-se em três modelos: Rompimento do Delta de Maré Vazante (Ebb-Tidal delta breaching); Quebra da 
plataforma do Pontal arenoso (Spit Plataforma breaching) e Migração de canal e quebra do Pontal arenoso (Inlet migration and Spit breaching).

A desembocadura do rio Sergipe pode ser enquadrada no modelo 3: Rompimento do Delta de Maré Vazante (Ebb-Tidal delta breaching). Esse modelo ocorre em desembocaduras que possuem posições de canais estáveis, mas cujos canais de marés vazantes principais migram ciclicamente a sotamar. A direção dominante do transporte longitudinal nesses locais produz um acúmulo preferencial de sedimentos do lado a updrift (barlamar do sentido da deriva litorânea) do delta de maré vazante. A acumulação de sedimentos provoca uma deflexão a downdrift (sotamar do sentido da deriva) do principal canal de vazante, que em algumas entradas pode vir a colidir contra a linha de costa a sotamar. Esse padrão de migração de canal geralmente induz a erosão ao longo da praia adjacente, conforme Santos (2012) mostrou a partir da análise evolutiva do Bairro Coroa do Meio/Aracaju/ SE. Uma deformação grave do canal principal produz escoamento na entrada que é hidraulicamente ineficiente. Eventualmente, essa condição resulta na descarga vazante, sendo desviado para um caminho em direção ao mar mais fácil através do delta de maré vazante (Figura 2).

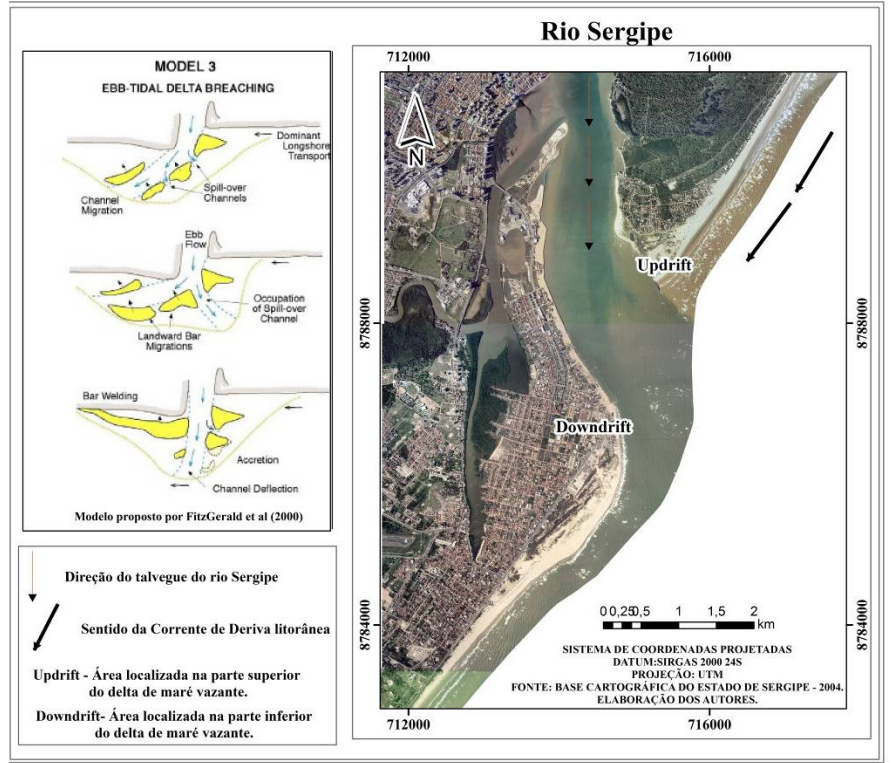

Figura 2 - Morfodinâmica da desembocadura do rio Sergipe. Fonte: organização dos autores.

A desembocadura do rio Vaza Barris segue o modelo 5: Quebra da Plataforma do Pontal Arenoso (Spit Plataforma breaching), conforme foi identificado por Oliveira e Melo e Souza (2015). Esse modelo ocorre em canais migratórios, onde a formação de um canal secundário na desembocadura promove o rompimento na plataforma do pontal arenoso, sendo que este novamente sofre acreção a partir do fornecimento de sedimentos existentes nos deltas de maré vazante e promove a contínua migração do canal. Com a erosão do pontal arenoso a updrift os sedimentos acumularam-se, dando origem ao pontal arenoso a downdrift, conforme é possível visualizar na Figura 3.

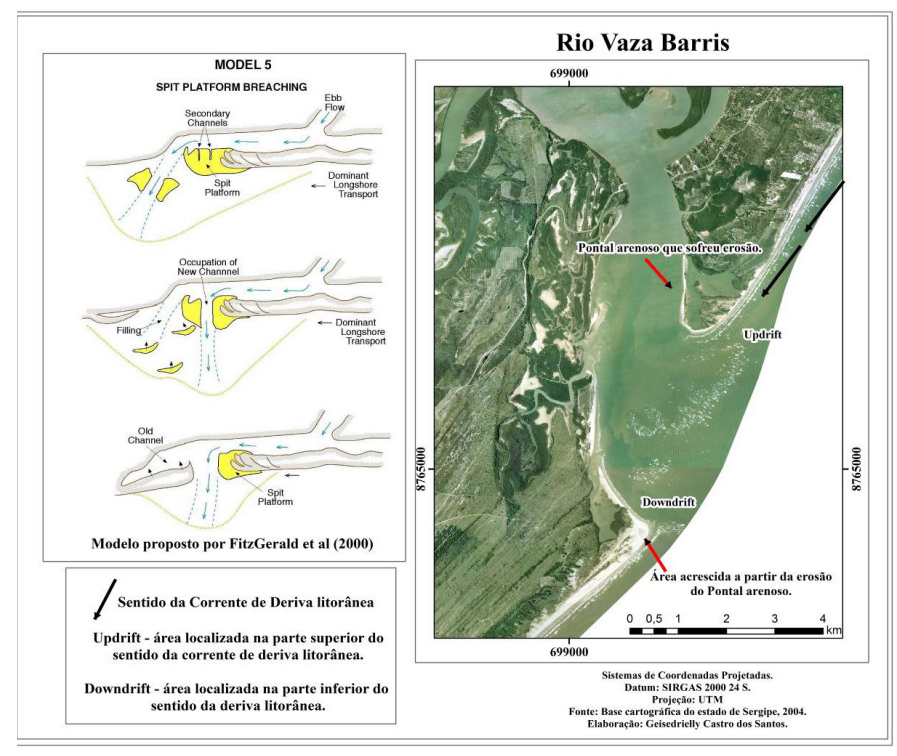

Figura 3 - Morfodinâmica da desembocadura do rio Vaza Barris. Fonte: organização dos autores.

A desembocadura dos rios Piauí/Real é representada pelo modelo 1 de transpasse de sedimentos: Migração de Canal e Quebra do Pontal Arenoso (Inlet migration and Spit breaching). 0 modelo proposto ocorre quando a vazão do canal fluvial é menos expressiva que a corrente de deriva litorânea. Esta promove o transporte dos sedimentos erodidos a barlamar, sendo depositados a sotamar e dando origem à formação de um pontal arenoso que acaba por obstruir parcialmente a desembocadura fluvial e provocando a alteração na orientação do fluxo (Figura 4). Quando o fluxo do canal se torna ineficiente, é possível que este rompa o pontal arenoso, contudo, se a formação do canal estiver associada à alternância entre ciclos de vazão normal e estiagem, o pontal arenoso pode estar soldado de tal forma que não mais será possível erodi-lo. A dinâmica existente nessa desembocadura é auxiliada pelo encontro de sentidos de derivas litorâneas efetivas diferenciadas, 0 que altera continuamente a migração do canal fluvial.
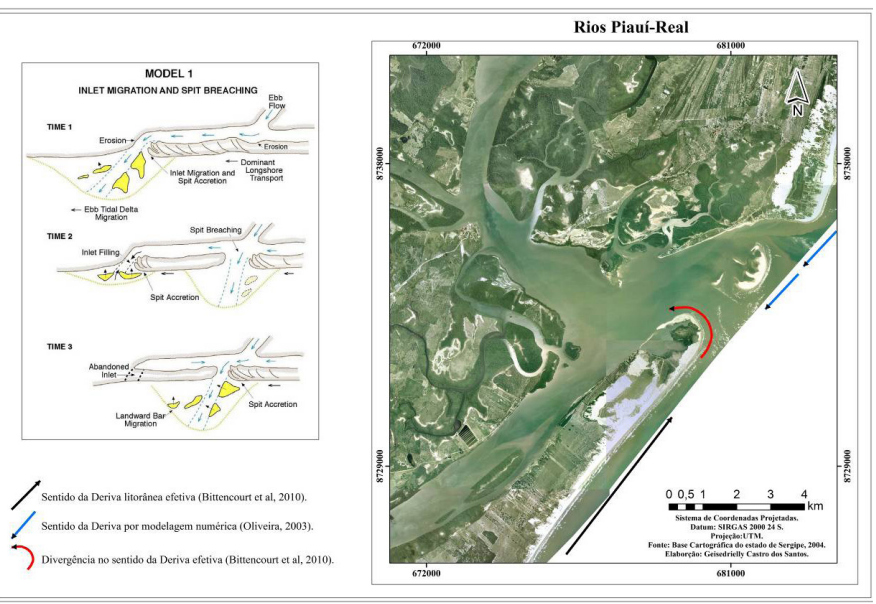

Figura 4 - Morfodinâmica da desembocadura dos rios Piauí/Real Fonte: organização dos autores. 
A partir dos processos morfodinâmicos que resultaram na configuração mais recente das zonas estuarinas localizadas nas desembocaduras que compõem a área de estudo, o presente trabalho visa compreender os principais processos responsáveis pelo surgimento das planícies de marés nesses locais, a partir da definição das séries ambientais geomorfológicas idealizadas por Thom (1982) e por alguns elementos que compõem a assinatura energética dos sistemas ambientais de acordo com Odum (1967). A partir do enquadramento da área de estudo, de acordo com as séries ambientais, é possível mensurar o grau de resistência e resiliência das planícies de marés em face de possíveis mudanças costeiras relativas às oscilações do nível do mar.

\section{Materiais e métodos}

Para a realização desta pesquisa foram utilizadas três etapas metodológicas: Coleta de dados relativos à assinatura energética dos ambientes estuarinos analisados; Processamento das imagens de satélite e fotografias aéreas; Integração e interpretação dos dados coletados.

\section{Coleta dos dados relativos à assinatura energética}

O conceito de assinatura energética para os sistemas ambientais costeiros foi idealizado por Odum (1967) e corresponde aos fatores que operam sobre um sistema ambiental e influenciam suas funções. 0 modelo clássico da assinatura energética para os ambientes de manguezais é constituído pelos seguintes fatores externos, ou, como chamado por Odum (1983 apud Twilley, 1995), "Forcing Functions": Energia solar; Temperatura do ar; Precipitação; Fornecimento de água fluvial; Regime de marés; e Nutrientes. Esses fatores correspondem ao input de energia sobre os sistemas ambientais e sua periodicidade influencia substancialmente no desenvolvimento dos manguezais. Contudo, existem os atenuantes que promovem a dissipação energética e assim comprometem o desenvolvimento estrutural dos manguezais, e estes são chamados de tensores, que podem ser de origem natural ou antropogênica.

Baseando-se nesse conceito, foram coletados para a área de estudo dados relativos às vazões históricas nas estações mais próximas das desembocaduras estudadas; e dados relativos à altura das ondas, regime de marés, direção do sentido da deriva litorânea efetiva, temperaturas e taxas de precipitação (para o período de 30 anos). A análise da vazão $\left(\mathrm{m}^{3} / \mathrm{s}\right)$ foi realizada a partir dos dados disponibilizados no site hidroweb da Agência Nacional de Águas (www.ana.gov.br), e posteriormente foram calculadas as médias das vazões históricas a cada 10 anos. Para o rio Piauí não foram encontradas todas as séries históricas de vazões conforme foram apresentadas para os demais rios da área de estudo. Os parâmetros oceanográficos foram extraídos de Pianca, Mazzini e Siegle (2010) a partir da reanálise efetuada dos dados de ondas para a costa brasileira. As médias de temperaturas e taxas de precipitação foram extraídas do site do Instituto Nacional de Meteorologia (www.inmet. gov.br). 0 sentido da deriva litorânea efetiva foi extraído das análises realizadas por Bittencourt et al. (2005) e Bittencourt et al. (2010).

A análise dos tensores ambientais foi realizada a partir da análise das fotografias aéreas do ano de 2004 e das imagens de satélite Rapideye dos anos de 2011 e 2014. As informações relativas às imagens utilizadas estão descritas na Tabela 1 a seguir:

\begin{tabular}{|c|c|c|}
\hline ANO & $\begin{array}{c}\text { TIPO DE } \\
\text { IMAGEM }\end{array}$ & ESCALA/RESOLUÇÃO \\
\hline 2004 & $\begin{array}{c}\text { Fotografias } \\
\text { aéreas }\end{array}$ & $1: 10.000$ \\
\hline 2011 & $\begin{array}{c}\text { Imagens } \\
\text { Rapideye }\end{array}$ & $\begin{array}{l}5 \mathrm{~m} \text { (multiespectral } \\
\text { compatível com a } \\
\text { escala de 1:25.000) }\end{array}$ \\
\hline 2014 & $\begin{array}{c}\text { Imagens } \\
\text { Rapideye }\end{array}$ & $\begin{array}{l}\text { compatível com a } \\
\text { escala de 1: 25.000) }\end{array}$ \\
\hline
\end{tabular}

Tabela 1 - Informações sobre as imagens de satélite e fotografias aéreas utilizadas na pesquisa.

Fonte: Felix; Santiago \& Cintra Consultoria (2009).

\section{Processamento das imagens de satélite e fotografias aéreas}

0 processamento das imagens de satélite e das fotografias aéreas foi dividido em duas etapas: retificação do datum horizontal e do georreferenciamento.

No SIG ArcGis v.12.2.1 foram feitas as importações das imagens de satélite dos anos de 2011 e 2014 e das fotografias aéreas do ano de 2004. Posteriormente foi feita a correção do datum horizontal de SAD 1969 para SIRGAS 2000.

Após a retificação do datum foi feita a retificação do georreferenciamento das imagens de satélite utilizando como referência as fotografias aéreas do ano de 2004, executadas pela SEPLAG/SE e que compõem a base cartográfica do estado de Sergipe. 0 georreferenciamento foi efetuado com auxílio do SIG QuantumGis v.2.0.1. Essa etapa permitiu a análise das imagens de satélite com a finalidade de identificação dos tensores ambientais e a utilização das fotografias aéreas para confecção dos modelos de morfodinâmica das desembocaduras e do mapa de indicadores geomórficos. A escolha das 
fotografias aéreas para serem apresentadas no presente artigo deveu-se à escala do material, o que permitiu maiores detalhes.

\section{Integração e interpretação dos dados}

A partir dos dados obtidos conforme descrito nas etapas metodológicas anteriores foi possível encaixálas de acordo com as séries ambientais geomorfológicas propostas por Thom (1982) e posteriormente compreender, a partir das suas características, o potencial de resistência e resiliência às mudanças ambientais costeiras, conforme proposto por ShaefferNovelli; Citrón-Molero; Soares (2002).

\section{Resultados e discussão}

\section{Assinatura energética das planícies de marés no litoral centro-sul sergipano}

Os fatores externos que compõem a assinatura energética das planícies de marés e responsáveis pela configuração desses ambientes (conforme descreve Thom, 1982), foram estruturados nesta pesquisa para compreender a dinâmica a partir das séries ambientais na área de estudo, e são aqui apresentados a partir da dinâmica climática e fluviomarinha.

A dinâmica climática da área de estudo está representada pelas temperaturas médias, taxas de precipitação e de evapotranspiração potencial - ETP (Tabela 2).

\begin{tabular}{|lccc|}
\hline & & & \\
Estaçōes & $\begin{array}{c}\text { 1961-1990 } \\
\text { Estimatológicas }\end{array}$ & $\begin{array}{c}\text { Shaeffer-Novelli } \\
\text { et al., 1990 }\end{array}$ \\
\cline { 2 - 4 } & $\begin{array}{c}\text { Precipitaçāo } \\
\text { acumulada (mm) }\end{array}$ & $\begin{array}{c}\text { Temperatura } \\
\text { anual }\left({ }^{\circ} \mathrm{C}\right)\end{array}$ & ETP \\
\hline Aracaju & 1.600 & 26 & 1.200 \\
Itabaianinha & 1.200 & 28 & 1.500 \\
\hline
\end{tabular}

Tabela 2 - Dados climáticos da área de estudo

Fonte: www.inmet.gov.br

A evapotranspiração potencial corresponde à quantidade de precipitação necessária para suprir as necessidades de água da vegetação (Fernandes; Foster, 2006). Conforme análise dos dados constantes na Tabela 2, foi possível verificar que as normais climatológicas médias de precipitação (para o período de 1960 a 1990) para o trecho analisado variaram entre 1.600 a $1.200 \mathrm{~mm}$, e a temperatura média variou entre $26^{\circ} \mathrm{C}$ e $28^{\circ} \mathrm{C}$. Shaeffer-
Novelli et al. (1990) calcularam para o trecho analisado uma taxa de evapotranspiração potencial entre 1.100 e $1.500 \mathrm{~mm}$. Em comparação com os dados obtidos de precipitação acumulada e a necessidade real dos ambientes de planícies de marés, concluiu-se que parte da área de estudo, em especial o litoral sul (desembocaduras dos rios Vaza Barris e Piauí-Real), possui um déficit de chuvas necessárias ao desenvolvimento estrutural dos bosques de mangue. Em contrapartida, Aracaju possui chuvas acima do necessário, conforme o comparativo efetuado. Essa análise da dinâmica climática influencia diretamente nos fluxos hídricos e posteriormente na atuação dos componentes oceanográficos sobre os sistemas estuarinos.

A dinâmica fluviomarinha da área de estudo está representada pela vazão nas desembocaduras fluviais e pelos componentes oceanográficos: altura das ondas, regime de marés e direção do sentido da deriva litorânea efetiva.

A partir dos dados coletados sobre as vazões dos cursos fluviais verificou-se que as médias históricas dos rios que compõem a área de estudo foram muito baixas, com exceção do rio Vaza Barris (Tabela 3). As médias das vazões históricas foram de: $4,35 \mathrm{~m}^{3} / \mathrm{s}$ para o rio Sergipe; $10,28 \mathrm{~m}^{3} / \mathrm{s}$ para o rio Vaza Barris; $0,59 \mathrm{~m}^{3} / \mathrm{s}$ para o rio Piauí e $2,5 \mathrm{~m}^{3} / \mathrm{s}$ para o rio Real.

\begin{tabular}{|c|c|c|}
\hline \multicolumn{3}{|c|}{ VAZŌES MÉDIAS NA DÉCADA (m³/s) } \\
\hline \multirow{5}{*}{ Rio Sergipe } & 1970 & 8,09 \\
\hline & 1980 & 6,32 \\
\hline & 1990 & 2,36 \\
\hline & 2000 & 2,52 \\
\hline & 2010-2015 & 2,44 \\
\hline \multirow{5}{*}{$\begin{array}{c}\text { Rio Vaza } \\
\text { Barris }\end{array}$} & 1970 & 14,45 \\
\hline & 1980 & 12,95 \\
\hline & 1990 & 8,8 \\
\hline & 2000 & 7,79 \\
\hline & $2010-2015$ & 7,43 \\
\hline \multirow{4}{*}{ Rio Piauí } & 1950 & 1,32 \\
\hline & 1960 & 0,86 \\
\hline & 2012 & 0,10 \\
\hline & 2013 & 0,10 \\
\hline \multirow{5}{*}{ Rio Real } & 1970 & 2,3 \\
\hline & 1980 & 4,1 \\
\hline & 1990 & 2,3 \\
\hline & 2000 & 2,0 \\
\hline & $2010-2015$ & 1,6 \\
\hline
\end{tabular}


Quando se compara o histórico das vazões com os dados de altura das ondas e regime de marés, é possível identificar a predominância dos agentes modeladores oceanográficos sobre a dinâmica nas desembocaduras e por consequência nas zonas estuarinas. 0 regime de marés para a área de estudo é do tipo mesomarés com característica semidiurna (dois ciclos de marés enchentes e de vazantes ao dia). As marés de sizígia apresentam amplitudes máximas em torno de 2,0m e mínimas de $0,0 \mathrm{~m}$. Com relação às ondas, Pianca, Mazzini e Siegle (2010) fizeram uma reanálise dos dados da NASA para a costa brasileira, apresentando um modelo de clima de ondas para um período de 11 anos (jan 1997 a dez 2007). Segundo esses autores, o setor no qual está inserido o estado de Sergipe apresentou ondas provenientes, principalmente de E/SE, geradas pelos ventos alísios durante o outono e o inverno. As ondas do quadrante $S$ também atuam no litoral sergipano, mostrando que as frentes frias podem afetar o clima de ondas desse setor. A altura das ondas varia entre 1 e $3 \mathrm{~m}$, chegando a $4 \mathrm{~m}$ no outono e a $4,3 \mathrm{~m}$ no inverno, sendo que essas ondas maiores são provenientes do quadrante SE. Durante a primavera e o verão, as ondas provenientes de $\mathrm{E} / \mathrm{NE}$ apresentam alturas de $1 \mathrm{a} 2 \mathrm{~m}$. No entanto, no verão as maiores ondas provêm do quadrante $\mathrm{N}$ com $2,6 \mathrm{~m}$, e na primavera provêm do quadrante SE com $3,8 \mathrm{~m}$.

O sentido da deriva litorânea efetiva no litoral sergipano contribui para a morfodinâmica das desembocaduras e na intensificação dos processos oceanográficos. De acordo com Bittencourt et al. (2010), o sentido da deriva efetiva no litoral sergipano é de NE/SW, com mudança no sentido na desembocadura dos rios Piauí/Real, que é de SW/NE, corroborado pela presença de um indicador geomórfico: o pontal arenoso na desembocadura do rio Real (Figura 4).

A análise das imagens do satélite Rapideye permitiu identificar os principais tensores antropogênicos existentes na área de estudo. Para o município de Aracaju os principais tensores antrópicos, ou seja, os fatores externos que podem colaborar para alterações nos ambientes de planícies de marés foram relacionados ao crescimento urbano no município, com maior expressividade na região da desembocadura do rio Sergipe (margem direita). A análise é corroborada por Santos (2012) quando esta autora associa o crescimento urbano à redução em $50 \%$ do ambiente de planície de maré existente no bairro Coroa do Meio. Nas proximidades da desembocadura do rio Vaza Barris (margem esquerda), a ocupação encontra-se em processo de expansão, contudo ainda ocorre de forma pontual, conforme verificado por Oliveira (2012). Para os municípios de Itaporanga D'Ajuda e Estância (margem direita do rio Vaza Barris e esquerda do rio Piauí, respectivamente) os principais tensores antrópicos são a expansão imobiliária e empreendimentos de aquicultura, e este último também constitui uma realidade para os municípios de Indiaroba e Santa Luzia do Itanhy (onde se localiza o estuário médio e superior do rio Piauí).

Além dos tensores antrópicos, a área de estudo também é afetada por tensores de origem natural. Bittencourt, Oliveira e Dominguez (2006) classificaram as desembocaduras da área de estudo como sendo de elevada variabilidade, ou seja, possuem sucessivos episódios de recuo e progradação de linha de costa. Esse estudo foi ratificado pelas análises em curto e médio prazos realizadas por Rodrigues (2008), Santos (2012) e Oliveira (2012).

O Quadro 1 faz uma síntese dos fatores ambientais e antrópicos externos que compõem parte da assinatura energética da área de estudo, fundamental para a classificação da mesma de acordo com as séries ambientais de Thom (1982).

\begin{tabular}{|c|c|c|c|}
\hline $\begin{array}{l}\text { Fatores } \\
\text { externos }\end{array}$ & $\begin{array}{l}\text { Desembocadura } \\
\text { do rio Sergipe }\end{array}$ & $\begin{array}{l}\text { Desembocadura } \\
\text { do rio Vaza Barris }\end{array}$ & $\begin{array}{l}\text { Desembocadura } \\
\text { dos rios Piauí/Real }\end{array}$ \\
\hline $\begin{array}{l}\text { Temperatura } \\
\text { média }\left({ }^{\circ} \mathrm{C}\right)\end{array}$ & 26 & $26-28$ & $26-28$ \\
\hline $\begin{array}{l}\text { Precipitaçāo } \\
(\mathrm{mm})\end{array}$ & 1.600 & $1.600-1.200$ & 1.200 \\
\hline ETP & 1200 & $1.200-1.500$ & 1.500 \\
\hline $\begin{array}{c}\text { Vazāo média } \\
\left(\mathrm{m}^{3} / \mathrm{s}\right)\end{array}$ & 4,35 & 10,28 & $0,59-2,5$ \\
\hline Deriva litorânea & NE/SW & NE/SW & NE/SW e SW/NE \\
\hline Regime de maré & Mesomarés & Mesomarés & Mesomarés \\
\hline Altura das ondas & $1-4 m$ & $1-4 m$ & $1-4 m$ \\
\hline $\begin{array}{l}\text { Tensores } \\
\text { antrópicos e } \\
\text { ambientais }\end{array}$ & $\begin{array}{l}\text { Crescimento } \\
\text { urbano e } \\
\text { mudanças na } \\
\text { dinâmica da linha } \\
\text { de costa. }\end{array}$ & $\begin{array}{l}\text { Expansāo urbana, } \\
\text { aquicultura e } \\
\text { mudanças na } \\
\text { dinâmica da linha } \\
\text { de costa. }\end{array}$ & $\begin{array}{l}\text { Expansāo urbana, } \\
\text { aquicultura e } \\
\text { mudanças na } \\
\text { dinâmica da linha } \\
\text { de costa. }\end{array}$ \\
\hline
\end{tabular}

Quadro 1 - Síntese dos fatores externos componentes da assinatura energética da área de estudo.

Fonte: www.ana.gov.br

Orgazação das autoras.

\section{Classificação das desembocaduras de acordo com as séries ambientais de Thom (1982)}

A partir dos dados expostos é possível classificar a área de estudo da seguinte forma:

Desembocadura do rio Sergipe: 0 comparativo da dinâmica climática e fluviomarinha associado ao processo morfodinâmico de formação da área em estudo permitiu classificar os ambientes de planícies de marés que se desenvolveram nessa zona estuarina como do tipo: Ambiente dominado por ondas (Figura 5).

De acordo com Thom (1982), nos ambientes dominados por ondas ocorrem elevada energia das ondas e pouca descarga fluvial. Ilhas barreiras e/ou baías barreiras são características desses ambientes. 
Existe um variável grau de modificações das formas de relevo pelo regime de marés. A vegetação halófita (mangue) ocorre nas margens das lagunas formadas nessas costas, conforme é possível verificar na Figura 6.

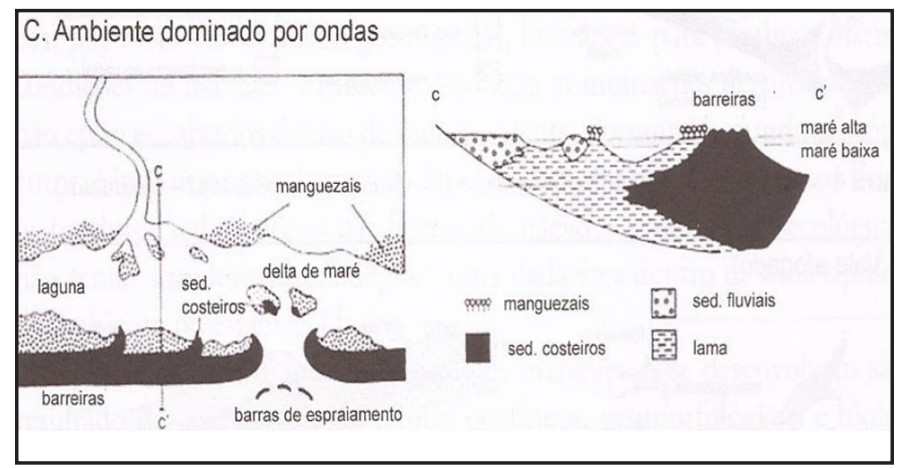

Figura 5 - Série ambiental III - Ambiente dominado por ondas. Fonte: Woodroffe (1982 apud VALE, 2004).
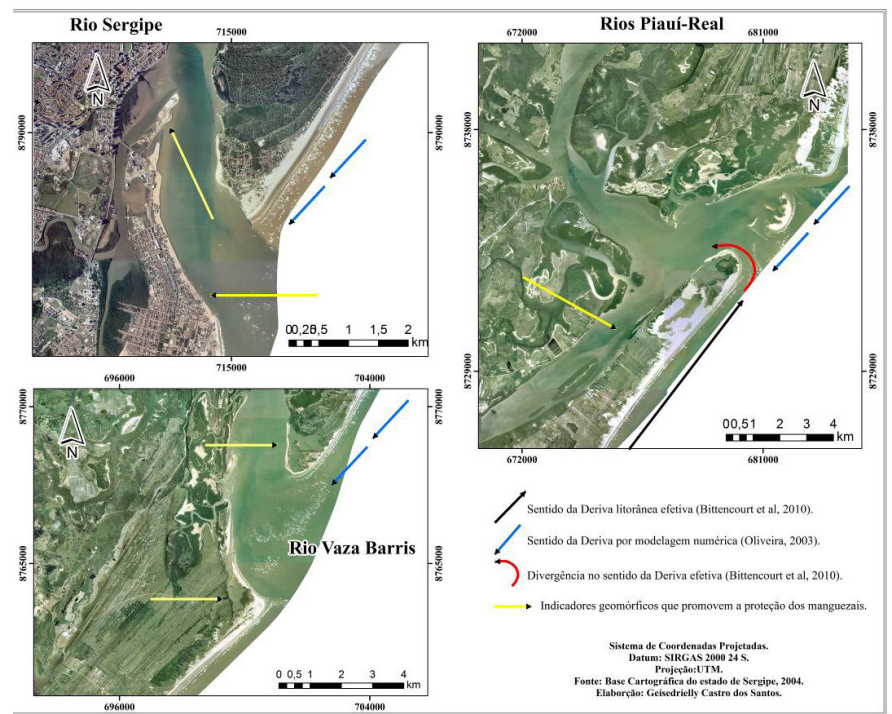

Figura 6 - Indicadores geomórficos que protegem as planícies de marés da ação direta das ondas.

Fonte: organização dos autores.

Desembocadura do rio Vaza Barris: a dinâmica da vazão fluvial diferenciada em relação às demais analisadas e em comparação aos processos morfodinâmicos da área de estudo (conforme descrito em Oliveira e Melo e Souza, 2015) permite classificar a área em questão como do tipo: Ambiente dominado por ondas e rio (Figura 7).

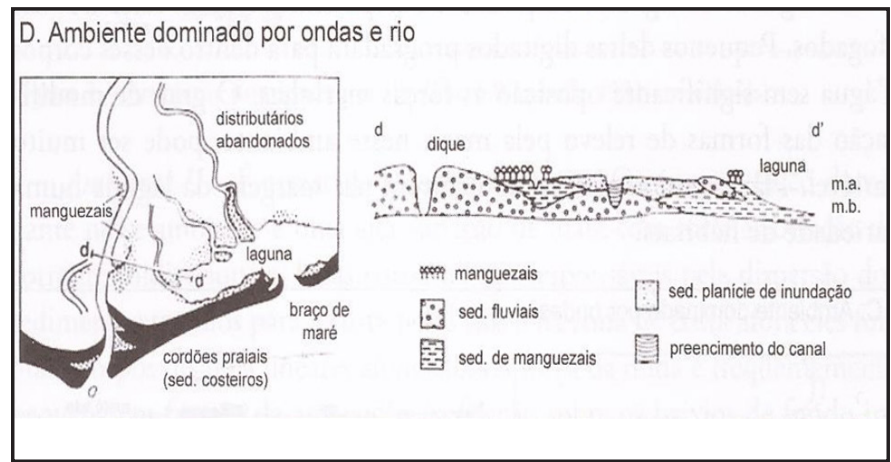

Figura 7 - Série ambiental IV - Ambiente dominado por ondas e rio. Fonte: Woodroffe (1982 apud VALE, 2004).
Na proposta de Thom (1982), esses ambientes são caracterizados por elevada energia das ondas e descarga fluvial. Os sedimentos transportados pelos rios são rapidamente redistribuídos ao longo da planície costeira. A colonização por mangue ocorre ao longo dos canais distributários abandonados em áreas próximas à foz $\mathrm{e}$ nas lagunas adjacentes, conforme é possível visualizar na Figura 7.

Desembocadura dos rios Piauí/Real: a análise da dinâmica climática e fluviomarinha mostrou a inexpressividade das vazões médias dos rios que configuram a desembocadura em análise e mostraram a importância da deriva litorânea efetiva que atua sobre esse ambiente assim como da energia das ondas no local. Dentro da classificação de Thom (1982), a área de estudo enquadra-se no Ambiente dominado por ondas (Figura 5). Fato corroborado pela análise da Figura 6.

A partir da classificação da área de estudo de acordo com a proposta de Thom (1982) é possível mensurar o grau de resistência e resiliência dos ambientes de planícies de marés. Shaeffer-Novelli, Citrón-Molero e Soares (2002) associaram as séries ambientais descritas em Thom (1982) e a resistência e a resiliência dos manguezais a mudanças do nível do mar e mudanças em nível de paisagem local. A resistência corresponde ao tempo que o ambiente leva para mudar em resposta a um dado distúrbio na paisagem, já a resiliência corresponde ao tempo que o componente ambiental leva para se recuperar de uma mudança na paisagem (Quadro 2).

\begin{tabular}{|c|c|c|}
\hline $\begin{array}{c}\text { Configuraçōes } \\
\text { ambientais } \\
\text { (Thom, 1982) }\end{array}$ & $\begin{array}{c}\text { Resistência a } \\
\text { mudanças }\end{array}$ & $\begin{array}{c}\text { Resiliência em } \\
\text { nível de paisagem }\end{array}$ \\
\hline $\begin{array}{c}\text { Alta sedimentação e } \\
\text { marés baixas (Série I) }\end{array}$ & Alta & Alta \\
\hline $\begin{array}{c}\text { Alta sedimentação e } \\
\text { marés altas (Série II) }\end{array}$ & Alta & Alta \\
\hline $\begin{array}{c}\text { Alta sedimentação e } \\
\text { alta energia das ondas } \\
\text { (Série III) }\end{array}$ & Baixa & Maixa - Média \\
\hline $\begin{array}{c}\text { Alto fluxo de água doce } \\
\text { e alta energia das ondas } \\
\text { (Série IV) }\end{array}$ & Média \\
\hline Vales afogados & Alta & Alta \\
\hline
\end{tabular}

Quadro 2 - Resistência e resiliência das séries ambientais a mudanças.Fonte: Fonte: Modificado de Shaeffer-Novelli; Citrón-Molero; Soares (2002).

De acordo com as análises efetuadas, os ambientes dominados por ondas tendem a ter baixa resistência a perturbações na paisagem de quaisquer naturezas, mas em especial as mudanças relativas ao nível do mar. A sua resiliência varia de baixo a médio grau, ou seja, a recuperação dos ambientes, quando cessadas as perturbações, tendem a ser lentas e/ou moderadas, enquadrando-se nessas circunstâncias as desembocaduras dos rios Sergipe e Piauí/Real. 
Com relação aos ambientes dominados por ondas e rios (no qual se enquadra a desembocadura do rio Vaza Barris), estes tendem a possuir média resistência a mudanças na paisagem e resiliência moderada a alta. 0 que demonstra que a atuação de fatores em sentidos opostos promove maior estabilidade dos ambientes de planícies de marés.

Destacam-se como principais agentes modificadores das paisagens os tensores antrópicos e ambientais (dentro dos sistemas ambientais estes correspondem aos fatores dissipadores de energia), representados nessa pesquisa pelo crescimento urbano, atividades econômicas e dinâmicas de elevada variabilidade das linhas de costas associadas às desembocaduras analisadas.

\section{Considerações finais}

A partir da pesquisa realizada verificou-se que os fatores externos que compõem a assinatura energética, responsável pela estruturação das planícies de marés, são semelhantes nas três desembocaduras analisadas. Contudo, diferenças nas vazões fluviais foram determinantes para alterações nos processos morfodinâmicosqueatuamsobreaárea deestudo. Amédia histórica da vazão do rio Vaza Barris é mais expressiva que as demais, e, sendo assim, a modelagem dessa desembocadura sofre a influência contínua da energia das ondas e da descarga fluvial. As desembocaduras dos rios Sergipe e Piauí/Real possuem pequenas médias de vazões anuais, sendo estas dominadas pela energia das ondas e pela influência do sentido da deriva litorânea efetiva, como a desembocadura dos rios Piauí/Real, que possui sentidos opostos de deriva efetiva nas margens direita e esquerda, sendo estas comprovadas pelos indicadores geomórficos.

Conforme as características apresentadas pelas assinaturas energéticas, a área de estudo foi classificada nas séries ambientais de Thom (1982): Ambientes dominados por ondas (desembocadura dos rios Sergipe e Piauí/Real) e Ambientes dominados por ondas e rio (desembocadura do rio Vaza Barris). Essa classificação acompanha a análise a partir dos modelos de transpasse de sedimentos (Fitzgerald, D. M.; Kraus, N.; C. Hands, 2000) para as referidas desembocaduras. Para o rio Vaza Barris a configuração da desembocadura aponta influência principal da migração do canal fluvial, formando um canal secundário; para o rio Sergipe ocorre a influência dos deltas de maré vazante e para a desembocadura dos rios Piauí/Real a influência predominante é da deriva litorânea efetiva aliada à energia das ondas que promove mudanças no escoamento do fluxo fluvial.

A classificação a partir das séries ambientais permitiu avaliar o grau de resistência e resiliência das planícies de marés estudadas às mudanças que podem ocorrer nas paisagens. Segundo análise de Shaeffer-Novelli, Citrón-Molero e Soares (2002), os ambientes dominados por ondas e rio tendem a possuir maior resistência e resiliência do que os ambientes dominados por ondas. A partir dessa constatação é possível associar os tensores antrópicos e ambientais como principais fatores que podem ser responsáveis por perturbações nas planícies de marés estudadas. 0 crescimento urbano constitui um fator de risco real para alterações nas planícies de marés da desembocadura do rio Sergipe, processo que pode constituir um risco também para as demais desembocaduras. A extrema variabilidade das linhas de costas associadas às desembocaduras estudadas também constitui um dos tensores que podem promover perturbações nos ambientes de planícies de marés, podendo ser intensificado pela expansão urbana.

A realização desta pesquisa fornece subsídios para o planejamento ambiental de regiões costeiras com presença de ambientes de planícies de marés, e para o monitoramento desses sistemas ambientais tendo em vista sua importância para a manutenção da biodiversidade e da proteção das áreas costeiras. 


\section{Referências}

ANGULO, R. J. (1990). O manguezal como unidade dos mapas geológicos. In: Simpósio de ecossistemas da costa sul e sudeste brasileira, v. 2, Águas de Lindóia. Resumos expandidos. São Paulo: ACIESP, p. 54-62.

BITTENCOURT, A. C. S. P.; DOMINGUEZ, J. M. L.; OLIVEIRA, M. B. (2006). Sergipe. In: MUEHE, D. (org.). Erosão e Progradação do Litoral Brasileiro. Brasília/DF: Ministério do Meio Ambiente, p. 214-218.

BITTENCOURT, A. C. S. P.; DOMINGUEZ, J. M. L.; MARTIN, L.; SILVA, I. R. (2005). Longshore transport on the northeastern Brazilian coast and implications to the location of large scale accumulative and erosive zones: An overview. Marine Geology, n. 219, p. 219-234.

BITTENCOURT, A. C. S. P.; LIVRAMENTO, F. C.; DOMINGUEZ, J. M. L.; SILVA, I. R. (2010). Tendência de longo prazo à erosão costeira num cenário perspectivo de ocupação humana: litoral norte do estado da Bahia. Revista Brasileira de Geociências. v. 40, n. 1, mar. p. 125-137.

FELIX, I. M.; SANTIAGO \& CINTRA CONSULTORIA (2009). RapidEye: a nova geração de satélites de observação da Terra. In: Anais XIV Simpósio Brasileiro de Sensoriamento Remoto, Natal, Brasil, 25-30 abril 2009, INPE, p. 7.619-7.622.

FERNANDES, D. S.; FOSTER, P. R. P. (2006). Cálculo da evapotranspiração potencial através do método de Thornthwaite e comparação com dados de reanálise de evaporação potencial do NCEP para a cidade de Pelotas/RS. XIV Congresso Brasileiro de Meteorologia, Florianópolis/SC.

FITZGERALD, D. M. (1982). Sediment bypassing at mixed energy tidal inlets. Proceedings 18th Coastal Engineering Conference, ASCE, p. 1.094-1.118.

FITZGERALD, D. M.; KRAUS, N. C.; HANDS, E. B. (2000). Natural Mechanisms of Sediment Bypassing at Tidal Inlets. US Army Corps of Engineers. ERDC/CHL CHETN-IV-30 December, p. 1-10.

ODUM, H. T. (1967). Work circuits and systems stress. In: YOUNG, H. (ed.). Mineral Cycling and Productivity of Forest. Orono: Univ. of Maine, p. 81-146.

OLIVEIRA, L. S. (2012). Evolução da paisagem costeira da Zona de Expansão de Aracaju/SE. 2012. 157 f. Dissertação (Mestrado em Geografia) - Universidade Federal de Sergipe, São Cristóvão/SE.

OLIVEIRA, L. S.; MELO e SOUZA, R. (2015). Morfodinâmica estuarina e variações do delta de maré-vazante no rio Vaza-barris/SE, Brasil. Revista Brasileira de Geomorfologia, São Paulo, v. 16, n. 4 (Out/Nov), p. 641-656.

PIANCA, C; MAZZINI, P. L. F.; SIEGLE, E. (2010). Brazilian offshore wave climate based on nww3 reanalysis. Brazilian Journal of Oceanography, v. 58 n. 1. p. 53-70.

PRITCHARD, D. W. (1967). What is an estuary, physical viewpoint. In: LAUF, G. H. Estuaries, n. 83. Washington, D.C.: AAAS, p. 1-5.

RODRIGUES, T. K. (2008). Análise das mudanças da linha de costa das principais desembocaduras do estado de Sergipe, com ênfase no rio Sergipe. 2008. 78 f. Dissertação (Mestrado em Geologia) - Universidade Federal da Bahia, Salvador/BA.

SANTOS, G. C. (2014). Derivações antropogênicas e evolução do manguezal nos bairros 13 de Julho e Jardins em Aracaju/SE. Revista Brasileira de Geografia Física, v. 7 n. 2, p. 278-290.

SANTOS, G. C. (2012). Dinâmica da paisagem costeira da Coroa do Meio e Atalaia - Aracaju/SE. 2012. 152 f. Dissertação (Mestrado em Geografia) - Universidade Federal de Sergipe, São Cristóvão/SE.

SCHAEFFER-NOVELLI, Y.; CINTRON, G.; ADAIME, R. R.; CAMARGO, T. M. (1990). Variability of mangrove ecosystem along the Brazilian coast. Estuaries, n. 13, p. 204-219.

SCHAEFFER-NOVELLI, Y.; CITRÓN-MOLERO, G.; SOARES, M. L. G. (2002). Chapter 9: Mangroves as indicators of sea level. In: HEALY, T.; WANG, Y.; HEALY, J. A. (eds.). Muddy Coasts of the World: Processes, Deposits and Function, Elsevier Science, p. 245-262.

SUGUIO, K.; MARTIN, L. (1978). Quaternary marine formations of the State of São Paulo and Southern Rio de Janeiro. Special Publicación n. 1. In: SUGUIO et al. (eds.). International Symposium on Coastal Evolution in the Quaternary. 55 p. THOM, B. G. (1967). Mangrove ecology and deltaic geomorphology: Tabasco, México. Journal of Ecology, n. 55, p. 301343.

TWILLEY, R. R. (1995). Properties of mangrove ecosystems related to the energy signature of coastal environments. In: HALL, C. Maximum power. Bouder, Colorado: University of Colorado Press, p. 3-18. 
VALE, C. C. (2004). Por uma metodologia para o estudo das áreas de manguezais: uma visão sistêmica. In: NUNES, J. 0. R.; ROCHA, P. C. (orgs.). Geomorfologia: aplicação e metodologias. São Paulo: Expressão Popular - UNESP, p. 117-132. ZENKOVICH, V. P. (1967). Processes of coastal development. London, $738 \mathrm{f}$. 